\title{
IJAL - An Open Access Journal
}

\author{
BY LARS ANDERSSON, HÅKAN JÖNSON E SANDRA TORRES
}

Running a scientific journal is a collegial effort. The editorial staff needs to work together with its board and with the external reviewers whose expertise they continuously have to call upon in order to guarantee that the research they are disseminating is of the highest quality possible. Running a journal is one of the most interesting challenges one can face as a member of the scientific community. This is why we decided to launch IJAL two years ago and why we have been working toward making this journal attractive to those aging researchers around the world who are interested in contributing to the expansion of the gerontological imagination ever since.

Through the past two years we have heard from colleagues around the world who are excited about the fact that IJAL is an open access (OA) journal that is available free of charge to anyone with internet access, and which is run by a group of researchers as opposed to an established publishing company. Our colleagues are in agreement that the possibilities to disseminate research results in this sort of outlet are endless. There are, however, as always, a group of skeptics who wonder if OA journals are here to stay or not. To this end we draw parallels to the time when the first cars appeared on our roads and people thought of them as sophisticated horse-drawn carriages. Although at different speeds, both vehicles fulfill the same purpose, which is why it took a while before cars developed an identity of their own. The same seems to be true of OA journals. A look at some of the available OA journals on the web shows that we are all still playing it safe. OA journals resemble, for example, traditional paper journals and this is most likely the case 
because they are still in the process of establishing themselves as an alternative outlet for scientific communication and need to have a format that is not only recognizable but one that is deemed 'respectable' as well. OA journals will, however, evolve in due time into a dissemination outlet of their own just like cars did decades ago and this evolvement will revolutionize the way in which we advance scientific knowledge in the future. This is why we launched IJAL as an OA journal from the start and why we are committed to exploiting the various possibilities that are inherent to this specific outlet (see, for example, the complimentary tables to Drs. Ong and Phillip's article available in this issue).

Running an OA journal is, however, a challenge in itself. Surely, to launch a journal without the support of a publishing company is manageable nowadays because there are numerous computer programs out there that can handle the submission process, the distribution of manuscripts to reviewers, the layout of the journal and so on and so forth. Our previous experience with working on other more traditional journals lead us, however, to believe that the challenges associated with this one venue are a bit more technical which is why we usually say that running an $\mathrm{OA}$ journal is not necessarily the same as running a traditional journal. It is, for example, one thing to know what PKP, DOAJ, Crossref, DOI, XML, ISI, SSCI stand for and another to understand how they all work. Decisions regarding the strategic development of a scientific journal that is OA need, therefore, to be made on a fairly continuous basis, which is why we at IJAL feel very fortunate for all of the lessons we have learned along the way. Needless to say, we look forward to learning more in the future as we work toward guaranteeing the high quality and user friendliness of the research results we are disseminating.

High quality is, after all, what every editorial staff and board of a scientific journal strives for regardless of whether they are an OA journal or not. Speaking of acceptance rates and the like seem therefore necessary. Acceptance (and/or rejection) rates are, without a doubt, one of the best indicators we have of whether a journal abides to high standards of quality or not. Only $30 \%$ of the manuscripts that we have received have been accepted for publication and although this is not a figure we have used to set a standard for ourselves, it surely illustrates 
that our standards are high. Thus, through the 'double' review process we use at IJAL (i.e. the fact that the manuscripts submitted are first 'approved' by the editorial board before we request the anonymous peerreview assessments from two experts in the area that the manuscript is tapping into) we are working to guarantee that the highest standards possible for a newly launched journal such as ours are followed. We believe that the content of our first three issues speaks to this end and look forward to hearing from those of you who are reading our journal and have comments and suggestions for us in this respect. 